\title{
A Novel Approach for Intensity Control of a Street Light
}

\author{
Brenda Lewis ${ }^{1}$, Christon Antony Cardoza ${ }^{2}$, Deekshitha N Jathan ${ }^{3}$, Flyacid Rodrigues ${ }^{4}$, Kusuma Prabhu ${ }^{5}$ \\ UG Student, Electronics \& Communication Department, Shri Madhwa Vadiraja Institute of Technology \& \\ Management, Udupi, India ${ }^{1,2,3,4}$
}

Assistant Professor, Electronics \& Communication Department, Shri Madhwa Vadiraja Institute of Technology \&

Management, Udupi, India ${ }^{5}$

\begin{abstract}
Nowadays, energy is an essential need for human life and for the development in all the sectors of economy. The drastic increase in population and rapidly decreasing conventional energy sources force us to think on promising way of non-conventional energy harvesting methods. Solar energy system is used to collect maximum power from sun. This proposal is to use the solar panels implemented in this project more efficiently and to carry out a realistic experimental approach to enhance the solar output power to a significant level. The power generation using piezoelectric sensor is used as another approach. When vehicles move, a large amount of kinetic energy is getting dissipated on roads. Hence, we make use of the vibration energy generated by the moving vehicles into a useable form of energy. Using the principle of piezoelectric effect the vibrational energy is converted into electrical form and stored as a backup source. This stored energy is used as a power source for the functioning of street lights and intensity control of the street lights. The status of the battery charging is also indicated.
\end{abstract}

Keywords: Intensity Control, Piezoelectric effect, Solar energy, Energy harvesting.

\section{INTRODUCTION}

Increasing concern of global warming and the depletion of fossil fuel reserves, many are looking at sustainable energy solutions to preserve the earth for the future generations. Other than hydro power, vibration and photovoltaic energy holds the most potential to meet our energy demands. Solar energy is present throughout the day but the solar irradiation levels vary due to sun intensity and unpredictable shadows cast by clouds, birds, trees, etc. The common inherent drawback of vibration and photovoltaic systems are their intermittent natures that make them unreliable. When a source is unavailable or insufficient in meeting the load demands, the other energy source can compensate for the difference by combining these two intermittent sources.

Solar energy is the viable source of renewable energy. Over the last 2-3 decades' solar energy systems is designed to collect maximum power from sun and convert into electrical power. It is now used in variety of fields such as industries, domestic purpose. Another form of energy is vibration energy is converted into electric energy by piezoelectric effect. To implement the technique more effectively, the concept of piezoelectricity has been introduced. Piezoelectric based energy harvest technology is applied to generate electricity from vibration. Piezoelectricity is the electric charge that accumulates in certain solid materials in response to applied mechanical stress. The proposed system is to make power generation more sustainable, economic and ecological by utilizing the advancement in the technology.

A solar panel is used as energy source and this stored energy is used as a power source for functioning of traffic lights and street lights. The idea here is focused on the street lights. In streets the lamps are glowing continuously throughout the night, large amount of power is wasted by unwanted use of power. This wastage of power is reduced by the implementation of this method. When a vehicle or human being is passed, it is detected by piezoelectric sensor unit and message signal is given to microcontroller unit. This unit will give signal to lamp drive circuit and the lamp glows brightly, thus the power can be saved by this technique.

\section{METHODOLOGY}

\section{A. Block diagram}

The block diagram of an proposed scheme is as shown in the below figure 1. The system has various parts such as solar panel, piezoelectric cells, bridge wave rectifier, filter, charging circuit, inverter circuit, piezoelectric sensor, vibration sensor, PIC microcontroller and loads. 


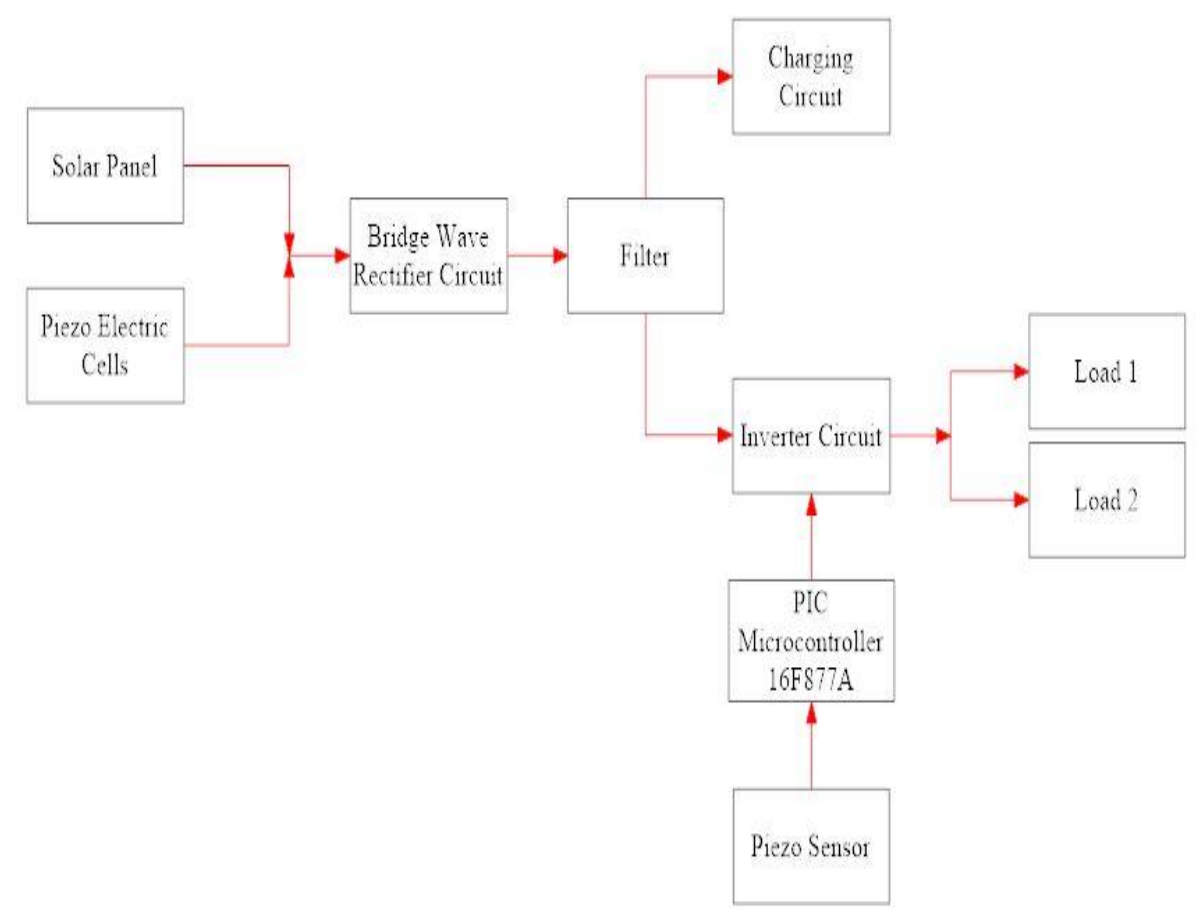

Fig. 1 Block Diagram of Advance Power Generation for Intensity Control of Street Light

Thesystem has mainly two parts power generation and intensity control of street light. The power generation includes solar panel and piezoelectric cells for generation of electrical power. The bridge rectifier, filter and charging circuit are used to convert the generated power to proper pure dc form and to make it to store in battery. The intensity control of street light involves piezoelectric sensor, vibration sensor and PIC microcontroller for controlling the intensity of the street light. Vibration sensor receives the input from thepiezoelectric sensor which is fed to the PIC microcontroller for the intensity control of the street light.

\section{III.RESULTS AND DISCUSSION}

A. Results

The power is generated for the intensity control of street light. The intensity of the street light is controlled. When there is no vehicle movement in the road the intensity will be $30 \%$ and when the vehicle interfaces the piezoelectric crystal on the road the intensity will be $100 \%$ is shown in fig. 2 and fig. 3 .

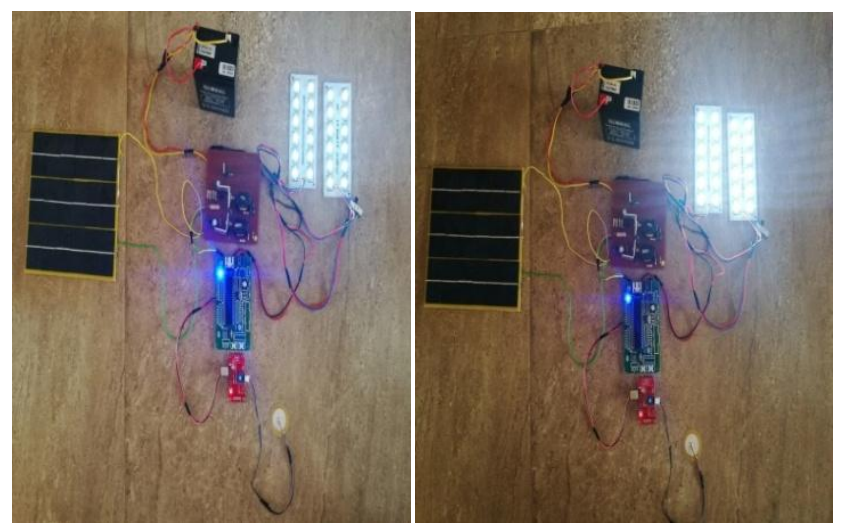

Fig.2 Street Light with 30\% Intensity Fig.3 Street Light with $100 \%$ Intensity

B. Advantages

The advantages of the system are

1) Reduces Electricity Bills 
2) No radiation harm and

3) Low maintenance cost

C. Limitation

1) The solar energy can be harnessed in a limited period as the sunlight is available only during the day time and sunny days; thus, power can be generated only in limited time period and the power as to be saved in batteries for later usage.

2) The batteries used to store solar power are very costly, huge sized and need to be replaced from time to time.

3) Piezoelectric sensors are not so effective may break if heavy weight is acted on it.

D. Future enhancement

The generation of the power can be improved by using piezo electric cells of larger size.

\section{IV.CONCLUSION}

Power issues are the biggest problem faced mainly in rural areas, these problems can be overcome. The advanced power generation system using solar panels is appropriate for street lighting in remote as well as urban areas. Solar powered automatic street light controller is one of the applications of electronic to increase the facility of life.

This implemented technique gives around $100 \%$ of intensity when any vehicles or human movement interfaces the piezoelectric sensor, else the street light will give intensity $30 \%$ during no vehicle movement. So throughout the world if we use this concept then it will designate the energy crisis to a larger extent. During rainy season using solar panels is not much effective. So, we have come up with an idea of using piezoelectric mats for power generation through which we can overcome the electric power scarcity all over the world

\section{ACKNOWLEDGMENT}

The student authors would like to thank Dr. Balachandra Achar H V, Professor and Head and Mrs. Kusuma Prabhu, Assistant Professor, Department of Electronics and Communication Engineering, SMVITM, Udupi for their exemplary guidance, monitoring and constant encouragement throughout the completion of this project.

We also express a deep sense of gratitude to thank Dr. Thirumaleshwara Bhat, Principal, SMVITM, Udupi for providing well organised infrastructure for the completion of our project.

\section{REFERENCES}

[1] Geffrey K. Ottman, Heath F. Hofmann, Archin C. Bhatt and George A. Lesieutre, "Adaptive Piezoelectric Energy Harvesting Circuit for Wireless Remote Power Supply", IEEE Transactions on Power Electronics, vol. 17 no.5, pp. 669-676, 2002.

[2] Cook-Chennault, K. A, Thambi, N., \& Sastry, A M. "Powering MEMS portable devices-A review of nonregenerative and regenerative power supply systems with special emphasis on piezoelectric energy harvesting systems". Smart Materials \& Structures, 17 (4), 33pp. (2008).

[3] A Khalig, P. Zeng, C Zheng. "Kinetic Energy Harvesting Using Piezoelectric and Electromagnetic Technologies-State of the Art. Industrial Electronics, IEEE Transactions on., vol. 57, no.3, pp. 850-860. March 2010..

[4] H. A. Sodano H. A. and D. J. Inman, "Comparison of piezoelectric Energy harvesting devices for recharging Batteries", LA-UR-04-5720, Journal of Intelligent Material Systems and Structures, 16(10), 799-807, 2005.

[5] P. Glynne-Jones, S. P. Beeby, and N. M. White, "Towards a piezoelectric vibration-powered micro generator," IEE Proc. Sci. Meas. Technol., vol.148, no. 2, pp. 68-72, 2001

[6] T. G. Engel, "Energy conversion and high power pulse production using miniature piezoelectric compressors," IEEE Trans. Plasma Sci., vol. 28, no. 5, pp. 1338-1340, Oct. 2000.

[7] Platt, S. R., Farritor, S., Garvin, K., \&Haider, H, "The use of piezoelectric ceramics for electric power generation within orthopedic implants." IEEE/ASME Transactions on Mechatronics,10(4), 455-461,2005.

[8] T. Starner and J.A. Paradiso, "Human-Generated Power for Mobile Electronics, Low-Power Electronics Design", C. Piguet,ed., CRC Press, chapter 45, 2004

[9] S. M. Metev and V. P. Veiko, Laser Assisted Microtechnology, 2nd ed., R. M. Osgood, Jr., Ed. Berlin, Germany: Springer-Verlag, 1998. 